\section{Teaching Basic Special Relativity in High School: The Role of Classical Kinematics}

\author{
Marcelo José Arlego* \\ UNICEN, Argentina
}

piniar@yahoo.com

\section{Dr. María Rita Otero}

UNICEN, Argentina

otero@exa.unicen.edu.ar

\section{Abstract}

In this work, we present a possible didactic sequence for the study of basic aspects of special relativity in high school. The sequence re-signifies the role of classical kinematics and Galileo's relativity principle. It has been implemented in four courses of two secondary schools in Argentina in 2014-2015 and in Colombia in 2016, with students aged 15-16, during 20 school hours, being the teacher a member of our research team.

\section{Keywords}

Teaching, special, relativity, high, school

•Received 1 December $2016 \bullet$ Revised 31 October $2017 \bullet$ Accepted 31 October 2017

\section{Introduction}

The special relativity (SR) is considered a difficult topic that is not generally taught in High School (HS). The root of these difficulties could be due to an inadequate, and often non-existent, school treatment of Galilean relativity and all that entails. For example, it is not possible to conceptualize the relativity of simultaneity without valuing the absolute role that simultaneity has in our daily life.

The investigations on the teaching of the SR have been mainly focused to university level (see for instance Hosson, C., Kermen, I., Parizzot, E. (2010); Pietrocola, M., Zylbersztajn, A. (1999); Scherr, R. E., Shaffer, P. S., Vokos, S. (2001)). In HS it is worth mentioning the works of Pérez, H., Solbes, J. (2006); Villani, A., Pacca, J. (1987). According to Dimitriadi, K. Halkia, K. (2012); Posner, G., Strike, A., Hewson, P., Gertzog, W. (1982), the HS students have a pre-Galilean view of the motion, which consider to be absolute. These ideas survive the school teaching of classical kinematics, and when attempts are made to teach relativistic kinematics, students are expected to become aware of the conceptual break between Galilean and modern physics (Villani, A., Arruda, S. (1998)). But how can they do so without the prior genesis of the relevant classical concepts?

In this work, we present a possible didactic sequence for the study of basic aspects of special relativity (SR) in high school that re-signifies the role of classical kinematics and Galileo's

* Corresponding author relativity principle (Otero, M. R, Arlego, M., Prodanoff, F. (2015)). The sequence has been implemented in four courses of two secondary schools in Argentina (Otero, M. R, Arlego, M., Prodanoff, F. $(2015,2016)$ ) and in Colombia in 2016, with students aged 15-16, during 20 school hours, being the teacher a member of our research team. The aim is that students develop in an operational way, not only predicatively or discursively, the following concepts: reference system, observer, motion, Galilean velocity addition, relativity principle, c-invariance, relativity of simultaneity, time dilation, contraction of lengths and relativistic addition of velocities.

\section{The Theory of Conceptual Fields}

In this work, the conceptualization is analysed within the Theory of Conceptual Fields (TCF) framework (see e.g. Vergnaud, G., (1990, 2013) for further details), in a classroom context, where the presented situations are essential to promote the emergence of the relevant concepts. According to the (TCF), a concept $\mathrm{C}$ is defined by a set of three interrelated elements: $\mathrm{C}=(\mathrm{S}$, OI, SR). Here $\mathrm{S}$ represents the set of situations that make the concept useful and meaningful, OI the set of operational invariants used "in situation" by individuals, and SR the set of symbolic, linguistic and graphical representations, that are used to express invariants, situations and procedures.

The OI are of two types: concepts-in-action (CA) and theorems-in-action (TA). These invariants organize the action of the subject and make it operational. A CA is a category, a predicate that is considered relevant to the situation. A TA is a proposition that the subject considers true about that situation. The OI are implicit and not comparable with concepts or scientific principles, because the latter are explicit, and their relevance and validity can be discussed. The TCF does not distinguish between everyday concepts and scientific concepts, the process of conceptualization has the same characteristics in all cases: it consists in identifying objects, their properties and their relationships (Vergnaud. G. (2013)).

According to the TCF there are two forms of knowledge in interaction. The operational form, which allows the subject to act in a situation, and the predicative form, which allows the subject to enunciate and designate objects, as well as communicate their knowledge. In the operational form, action does not only refer to their external manifestations, i.e. behavior, but also includes the operational and implicit aspects of the action: thought, decision making, anticipation and inferences. Consequently, teaching-learning cannot be reduced to the predicative form, nor can a concept be reduced to its definition.

Our research analyzes the activity of the subject in situation focusing on the process of conceptualization. For this reason, we use the framework of the TCC, identifying both the OI and SR. The analysis in terms of OI makes it possible to distinguish what characteristics of the situations are considered by the subject, what OI they put into play and what are the goals they are trying to achieve, as well as the rules and inferences they use to do it (Vergnaud, G. (2013)). 
There are no precedents in the literature of a didactic sequence for HS designed within the reference of the CCT, nor of the analysis of the conceptualization of basic concepts of the SR using this reference.

\section{Structure of the Sequence}

The sequence (Otero, M. R., Arlego, M. (2016)) is structured in three phases. The first phase is in turn divided in two parts (1a and 1b).

Phase 1a: Description of motion and relative velocity: This part refers to the classical (prerelativistic) kinematics and the Galileo's relativity principle. Here the motion analysis from different reference systems is proposed, allowing introducing the relativity from the beginning and avoid the concept of a privileged reference frame. After that, the relative velocity topic is addressed, based on daily life student's experience. This type of situations aims the emergency of the Galileo's law of velocities addition.

Phase 1b: Inertia and Galilean Relativity: Here situations that allow considering the inertia principle and Galilean relativity are presented. To this end, it is proposed to personally perform different actions like stay at rest, at uniform motion (respect to the floor), as well as braking accelerating or moving in a circle, with a pendulum hanging from the hand. With that it is intended that students "experience" the inertia and approach the idea of indistinguishability between rest and uniform translation. In the last situation of this phase, it is proposed to infe the state of motion of a wagon (ideally isolated) only with the help of a pendulum hanging from the wagon ceiling.

Phase 2: Transition from Galileo's to Einstein's relativity: The second part of the sequence consists in a transition to SR, which generalizes the relativity principle, introduces the c-invariance and the topic of the simultaneity.

Here the aim is to analyse the absolute character of the simultaneity, in a Galilean context, by means of situations involving different events with low-speed rubber bullets, which are requested to be analysed from different reference systems. This requires applying the concepts of Galilean relative motion and the relativity principle discussed in the first part, to solve kinematic meeting problems which are treated progressively from a numerical up to a symbolic and graphical level.

In the last part of the second phase similar situations but with light beams (instead of bullets) are presented. The corresponding meeting problem equations are solved by using the technique developed in the first part together with the c-invariance. In this way, the relativity of the simultaneity phenomenon emerges in a context involving light, bringing the entrance to the SR.

Note that this phase represents a transition because although the analysis with rubber bullets is incorrect in a fully relativistic framework (simultaneity is always a relative concept), it enables introducing the topic of simultaneity in a familiar context for students, as well as developing the technique to address the meeting problem for light.
Phase 3: Basic aspects of Einstein's relativity: This phase considers basic kinematical concepts of the SR. By using the relativity principle and the c-invariance, the time dilation, the length contraction and the relativistic addition of velocities are considered. The latter allows revisit the issue of bullets in a relativistic context, giving to the phenomenon of non-simultaneity a general character.

\section{Implementation and Results Analysis}

In this work, we focus on the first two phases of 2016 implementation (Colombia). We employ a qualitative methodology based on students' productions when they are faced with the situations. Thus, we analyze the conceptualization process from the point of view of the (TCF), by analyzing operational invariants (OI) as theorems in action (TA), and the representation systems (SR) (Otero, M.R., Fanaro, M.A., Sureda, P., Llanos, V.C., Arlego, M. (2014)).

In the following we present selected results of the distinct stages of the parts 1 and 2 , showing emergent TA from student's productions.

\section{Phase 1a results}

Here we analyse one (S2) of the three situations presented in this phase, which corresponds to relative motion and Galileo's speed addition.

The situation S2 is: "I am traveling by car on a straight road behind a car which is always at the same distance. I see the car of a friend of mine coming from the front. My travel partner says that this car is approaching us at $150 \mathrm{~km} / \mathrm{h}$, and since the speed limit on this road is $80 \mathrm{~km} / \mathrm{h}$, he says that my friend will be fined. I disagree, because we are traveling at the speed limit. To find out for sure we send a message to our friend in the other car, asking for his speed. Which is his response?"

$70 \mathrm{~km} / \mathrm{h}$

$$
x+80=150
$$

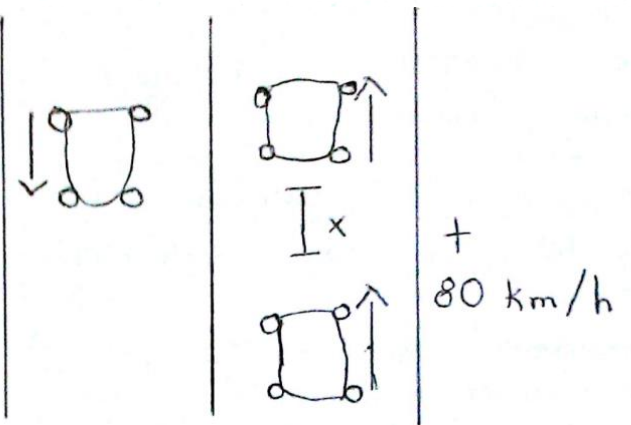

Figure 1. Drawing of a student representing the situation S2.

In Figure 1 we show a typical drawing made by the students about to S2. Relevant TA that we infer from the student's productions here are listed below. The relative frequencies are indicated between brackets. 
"The car coming to me seems to have more speed than mine. The speed of the car that passes me is smaller than mine" (28/65).

"The approaching velocity is the sum of their velocities" (47/65).

"If the cars are in the same direction, the approaching velocity is the subtraction of their velocities". (36/65).

\section{Phase $1 b$ results}

In this case we analyze one (S5) of the two situations presented in this part.

The situation S5 is: "Suppose we were locked in a train wagon or in a car and cannot see out, or take any external reference, we only have a pendulum. Can it help us to find out if we are moving?"

Here students make many drawings from inside the train, as it is illustrated in Figure 2. This suggests a conception of motion as relative and not absolute. Also, the principle of relativity emerges, as the following TA suggests:

"We cannot differentiate rest from uniform motion" (49/59). $(44 / 59)$.

"The pendulum moves in the opposite direction to the wagon when the speed changes"

$$
\text { "A pendulum helps to know how the car moves" (28/59). }
$$

Nuestro pendulo podria ayudarnos, solamente si el bagón donde nos encontraramos, frenara o Tomara una curva. Ya q el pendulo esta en movimiento rectilineo Uniforme y por esto se encontrara en reposo.

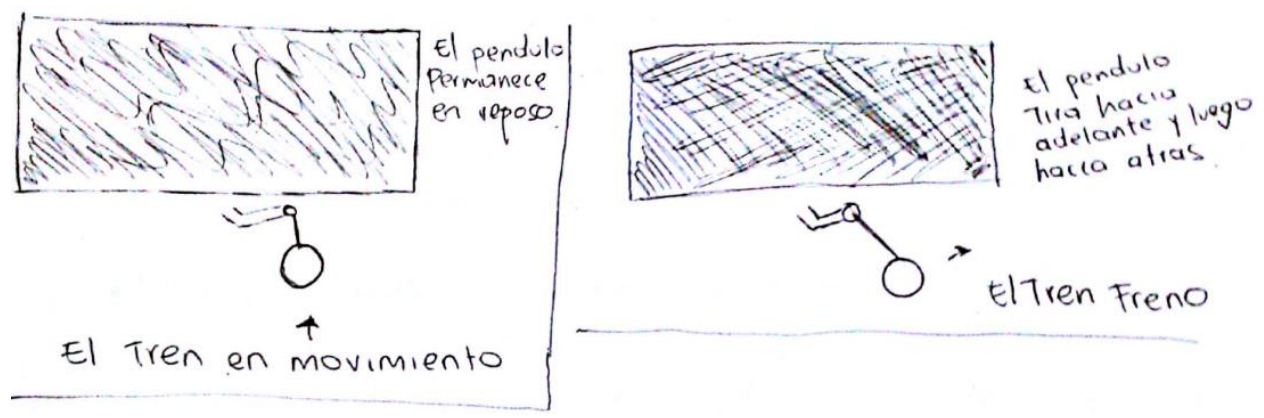

Figure 2. Representative drawing of a student about situation S5. Note that the point of view is from "inside", suggesting that this student considers the motion respect to the wagon. Text translation: "The pendulum could help us only if the wagon brakes or turns, but with uniform motion it is at rest".
Therefore, from the TA and the R in these situations we could conclude that there is a good approximation to the concept of equivalence between rest and uniform motion.

\section{Phase 2 results}

Here we analyze the situations S6 and S7 which comprise this phase. The first one is the following:

S6: An observer sits in the middle of an empty wagon. Another observer standing on the side of the road, determines that the car moves at a constant speed. The observer who is in the wagon has a device that can shoot rubber balls forward and backward at the same instant.

a) First analyze for each observer, without doing calculations, if the projectiles arrive at the same time at each side of the vehicle.

b) Complete a table for each observer and propose different speeds for the wagon and projectiles. c) After that calculate the meeting point (position and time) between bullets and walls of the wagon, for each observer, considering the different speed values proposed.

In the anticipation of part a) the relevant TA are:

"To the observer inside the car, bullets come at the same time" (56/59).

"To the observer outside the car bullets arrive at different times" (52/59).

The second theorem might be related with the common idea that the time to the left is smaller than to the right, because the projectile to the left goes to the wall of the wagon, while the projectile to the right follows the other wall. This theorem in action is so powerful that it completely masks the loss of simultaneity prediction, implicit in the anticipation. However, the subsequent use of tables and graphics software to analyze the meeting problem, facilitates the conceptualization of the Galilean addition of velocities, which in turn contribute to make explicit the absolute character of the simultaneity phenomenon, in a Galilean context. This is evident from the emergence of the following TA after calculations:

"To outside observers, left bullet speed is smaller than the right one" (58/58).

"The observer on the route measures the same time to both sides because the speeds and distances are compensated" (51/58).

Regarding S7, which is equivalent to S6 but replacing bullets by a light beam, in the anticipation, the opinions are divided, despite c-invariance is introduced by the teacher as an experimental fact. As before, the work with the tables and the analytical treatment of the meeting problem, facilitates in this case the introduction of the lack of simultaneity phenomenon, i.e. opposite to the purpose of S6. This is illustrated in student protocols of Figures $\mathbf{3 a}$ and $\mathbf{3 b}$ and the following emergent TA, after calculations:

"Light speed is the same for both observers." (55/55).

"Calculations show that light comes at separate times for outside observer." (48/55) 


\begin{tabular}{|c|c|c|c|c|c|}
\hline \multicolumn{3}{|c|}{ Observador en el Camión } & \multicolumn{4}{|c|}{ Observador en la Ruta } \\
\hline$v_{v}^{\prime}(\mathrm{m} / \mathrm{s})$ & $v_{t a}^{\prime}(\mathrm{m} / \mathrm{s})$ & $v_{t u}^{\prime}(\mathrm{m} / \mathrm{s})$ & $v_{v}(\mathrm{~m} / \mathrm{s})$ & $v_{L d}(\mathrm{~m} / \mathrm{s})$ & $v_{L i}(\mathrm{~m} / \mathrm{s})$ \\
\hline 0 & $C$ & $-C$ & 30 & $C$ & $-C$ \\
\hline 0 & $C$ & $-C$ & 25 & $C$ & $-C$ \\
\hline 0 & $C$ & $-C$ & 20 & $C$ & $-C$ \\
\hline 0 & $C$ & $-C$ & 15 & $C$ & $-C$ \\
\hline$C$ & $C$ & $-C$ & 10 & $C$ & $-C$ \\
\hline
\end{tabular}

"From inside, the light arrives at the same time; from outside, it arrives at different times, because light speed does not change"

Figure 3a. Table elaborated by a student proposing different velocities for the wagon and light beams to the right and to the left, respectively, from inside the wagon (first three columns) and the same from outside (last three columns).

\section{Dentro del ungón:}

$X P d=10$

$x P_{i}=-10$

$x l d \cdot c \cdot t$

$X L i=C t$

$\begin{array}{ll}X P d=X C_{d} & x P_{1}=x(i \\ 10=c . t & -10=-c t \\ t=\frac{10}{c} & t=\frac{10}{c}\end{array}$

orreccion

\section{Tuera del ragón:}

$X L_{d}=c t \quad x L_{i}=-c t$

$x P d=10+25 . t \quad x p i=-10+\angle 5 . t$

$x(d)=x p d$

$c t=10+25 t$

$x l_{i}=X P_{i}$

$10=(c-25) t$

$t=10$

$\overline{(c-25)}$

$-c t=-10+25 t$

$-10=(-c+25) t t$

$t=\frac{10}{(c+25)}$

\section{por que la velocidas de la lut no carbia}

Figure $\mathbf{3 b}$. student protocol showing the meeting point time calculation for both light beams, from inside and outside the wagon, respectively.

\section{Conclusions}

To summarize, in this work, we have presented a possible didactic sequence for the study of the basic aspects of special relativity (SR) in high school. The sequence gives a central role to classical Galileo's relativity principle as a natural starting point to Einstein's relativity. Preliminary results based on the analysis of "in situation" student's productions, suggest that a progressive transition to Einstein relativity as the proposed here, could facilitate the conceptualization phenomena like lack of simultaneity. The operative invariants related to classical Galilean cinematics are essential to enter to Einstein's relativistic kinematics. Consequently, it is necessary to approach the teaching of school kinematics toward the relativity of motion and reference systems, proposing everyday life situations that are not frequently analyzed, although we all have experience about them. Students are not always absolute or unable to conceptualize Galileo's relativity, but rather that the possibility of analyzing situations they know is not usually presented in the school setting. To learn the consequences of suspending the addition of velocities, it is necessary to be aware of it. Therefore, to learn the SR, it would not be possible to leave that genesis aside.

\section{References}

Dimitriadi, K. Halkia, K. (2012). Secondary Students' Understanding of Basic Ideas of Special Relativity, International Journal of Science Education, 34(16), 2565- 2582. http://dx.doi.org/10.1080/09500693.2012.705048.

Hosson, C., Kermen, I., Parizzot, E. (2010). Exploring students' understanding of reference frames and time in Galilean and special relativity. European. Journal of Physics, 31, 1527-1538. http://dx.doi.org/10.1088/01430807/31/6/017.

Otero, M.R., Fanaro, M.A., Sureda, P., Llanos, V.C., Arlego, M. (2014). La Teoría de los Campos Conceptuales y la conceptualización en el aula de Matemática y Física. Editorial Dunken.

Otero, M. R., Arlego, M. y Prodanoff, F. (2015). Design, analysis and reformulation of a didactic sequence for teaching the Special Theory of Relativity in high school. Revista Brasileira de Ensino de Física, 37(3), 3401 http://dx.doi.org/10.1590/S1806-11173731891.

Otero, M. R., Arlego, M. y Prodanoff, F. (2016). Teaching the basic concepts of the Special Relativity in the secondary school in the framework of the Theory of Conceptual Fields of Vergnaud. Il Nuovo Cimento, 38C http://dx.doi.org/10.1393/ncc/i2015-15108-0.

Otero, M. R. y Arlego, M. (2016). Secuencia para enseñar la Teoría Especial de la Relatividad en la Escuela Secundaria. Ed. UNICEN. Argentina.

Pérez, H., Solbes, J. (2006). Una propuesta sobre enseñanza de la relatividad en el bachillerato como motivación para el aprendizaje de la física. Enseñanza de las Ciencias, 24(2), 269-279.

Pietrocola, M., Zylbersztajn, A. (1999). The use of the principle of relativity in the interpretation of phenomena by undergraduate students. International Journal of Science Education, 21(3), 261-276.

Posner, G. J., Strike, K. A., Hewson, P. W. and Gertzog, W. A. (1982), Accommodation of a scientific conception: Toward a theory of conceptual change. Science Education, 66: 211-227. doi:10.1002/sce.3730660207

Scherr, R. E., Shaffer, P. S., Vokos, S. (2001). Student understanding of time in special relativity: Simultaneity and reference frames. American Journal of Physics, Physics Education Research Supplement, 69 (S1), 24-35.

Vergnaud, G. (1990). La théorie des champs conceptuels. Recherches en Didactique des Mathématiques, 10(23), 133-170. La Pensée Sauvage, Marseille.

Vergnaud, G. (2013). Pourquoi la théorie des champs conceptuels? Infancia y Aprendizaje, 36(2), 131-161.

Villani, A., Pacca, J. (1987). Students'spontaneous ideas about the speed of light. International Journal of Science Education, 9, 55-66.

Villani, A., Arruda, S. (1998). Special Theory of Relativity, Conceptual Change and History of Science. Science \& Education, $7(2), 85-100$.

\section{的}

IJPCE - International Journal of Physics and Chemistry Education, 9(1), 9-12

www.ijpce.org 